УДК 656.072

КРИТЕРИЙ ЭФФЕКТИВНОСТИ РЕКОНСТРУКЦИИ ЛИНИИ ДЛЯ СКОРОСТНОГО ДВИЖЕНИЯ ПАССАЖИРСКИХ ПОЕЗДОВ

Старш. преп. Т. А. Дубровская, канд. техн. наук П. В. Ковтун

\title{
ANALYSIS OF THE INFLUENCE OF AN ABSOLUTE ACCELERATION ON THE SPEED OF MOVEMENT OF PASSENGER TRAINS
}

\author{
Sr. Lecturer T. A. Dubrovskaya, PhD (Tech.) P. V. Kovtun
}

DOI: https://doi.org/10.18664/1994-7852.187.2019.196327

Одной из основных задач при введении скоростного движения на направлениях железной дороги Республики Беларусь (v = 141 - 200 км/ч) является его техникоэкономическое обоснование. Для решения этой задачи необходимо рассмотреть структуру критерия эффективности в случае реконструкиии линии для скоростного движения пассажирских поездов и определить общую эффективность использования нового подвижного состава. В расчет эффективности реконструкции входят суммы инвестиций или капитальных вложений, необходимых для реализачии проектного решения; годовые текущие затраты, возникающие в процессе реализаџии проекта и затем его реализации; приведены строительно-эксплуатачионные расходы; доходы или прибыль, полученные от внедрения проекта. Определение общей эффективности внедрения скоростного движения позволит сказать о приблизительных сроках окупаемости проекта и затрат на него.

Ключевые слова: железнодорожный транспорт, скорость, экономика, эффективность, реконструкция.

The economic efficiency of investments in railway transport in the new economic conditions should be fully justified. The task is not so simple. It causes some difficulties, because it is not always at the disposal of the decision-maker, at an early stage of design are sufficiently reliable and well-systematized initial data. 
The General trends of the analysis of recent studies are that in times of market economy one of the main tasks of any innovation is its cost and competitiveness. According to existing forecasts, high-speed traffic in the near future can cover much wider sector of passenger traffic than highspeed, as its organization is not associated with the construction of a new line, although it requires significant reconstruction costs. Correctly determine the amount of capital investment in the reconstruction-this is the main task of the economic justification of the introduction of high-speed traffic.

One of the main tasks in the introduction of high - speed traffic on the directions of the railway of the Republic of Belarus $(v=141-200 \mathrm{~km} / \mathrm{h})$ is its feasibility study. To solve this problem, it is necessary to consider the structure of the efficiency criterion in the case of reconstruction of the line for high-speed passenger trains and determine the overall efficiency of the use of new rolling stock. The calculation of the efficiency of reconstruction includes the amount of investment or capital investment required for the implementation of the project solution; annual current costs arising in the process of project implementation and then its implementation; construction and operating costs are given; income or profit received from the implementation of the project. Determining the overall efficiency of the implementation of high-speed traffic will allow us to say about the approximate payback period of the project and its costs.

Keywords: railway, speed, economy, efficiency, reconstruction.

Введение. Технико-экономическое обоснование целесообразности технического совершенствования железнодорожной инфраструктуры требует инвестиционных вложений, основывается на системе показателей, которые можно объединить в две группы: натуральные и стоимостные показатели.

Натуральные показатели характеризуют технические или технологические преимущества проектного решения. Это могут быть технические параметры проекта: руководящий уклон, длина приемо-отправочных путей, весовая норма, класс железнодорожного пути и т. д. Или параметры, имеющие важное эксплуатационное значение: скорость, расход электроэнергии, расходы по содержанию постоянных устройств и прочее. Определяющее значение для выбора проекта, в который будут вкладываться инвестиции, при всех прочих равных условиях имеют стоимостные показатели.

К стоимостным показателям, которые обычно рассматриваются при экономическом обосновании капитальных вложений, относятся: суммы инвестиций или капитальных вложений, необходимые для реализации проектного решения; годовые текущие затраты, возникающие в процессе реализации проекта; приведенные строительно-эксплуатационные расходы и доходы, получаемые от реализации проекта.

В состав суммы капитальных вложений или единовременных затрат входят инвестиции в их денежном эквиваленте. Текущие расходы и затраты включают все виды расходов, связанных с эксплуатацией вновь построенных или реконструированных инвестиционных объектов. В отличие от капитальных вложений текущие расходы рассчитываются обычно за годовой период эксплуатации.

Анализ последних исследований и публикаций. Проблемами экономического обоснования капитальных вложений при реконструкции железных дорог для введения скоростного движения на существующих железнодорожных линиях занимались многие известные ученые: Б. А. Волков [1], А. Ю. Чередниченко [2], Н. Б. Курган [3], В. П. Зозуляк [4], А. А. Босов [5], Б. Н. Лапидус, Н. П. Терешина [6], С. В. Мямлин [7], А. С. Блохина [8] и другие.

Общие тенденции анализа последних исследований сводятся к тому, что во времена рыночной экономики одной из 
главных задач любой инновации является ее стоимость и конкурентоспособность. По существующим прогнозам, скоростное движение в ближайшем будущем может охватить значительно шире сектор пассажирских перевозок, чем высокоскоростное, так как его организация не связана со строительством новой линии, хотя и требует существенных затрат на реконструкцию. Правильно определить величину капитальных вложений в реконструкцию - вот основная задача экономического обоснования введения скоростного движения.

Среди зарубежных ученых, занимающихся этой проблемой, можно выделить [9, 10].

\section{Определение цели и задачи}

исследования. Определить общую экономическую эффективность и срок окупаемости введения нового подвижного состава «Stadler» на железной дороге
Республики Беларусь с целью повышения скоростей движения пассажирских поездов.

Для решения этой задачи необходимо:

- рассмотреть структуру критерия эффективности реконструкции линии скоростного движения пассажирских поездов;

- определить общую эффективность использования нового подвижного состава.

\section{Основная часть исследования.} Рассмотренная задача - внедрение скоростного движения - относится к государственному уровню и поэтому устанавливается общественная эффективность инвестиций. При этом, в качестве основной части, как результат от увеличения скоростей движения пассажирских поездов, может быть принята дополнительная плата пассажиров за сокращение времени поездки

$$
C_{\text {пас-год }}=365 n_{n a c} \cdot m \cdot \alpha_{\text {зап }} \cdot \Delta T \cdot e_{\text {пас-час }} \cdot 10^{-6}, \text { млН. бел. руб./Год, }
$$

где $n_{\text {пас. }}$ - количество скоростных пассажирских поездов в сутки;

$m$ - вместимость поезда, чел.;

$\alpha_{\text {зап }}-$ коэффициент использования вместимости поезда;

$e_{\text {пас.час }}-$ стоимость пассажиро-часа, бел. руб.;

$\Delta T$ - сокращение времени нахождения пассажиров в дороге (в оба направления), час.

При сравнении вариантов проектных решений, например, по выбору вида подвижного состава для скоростных поездов, можно использовать стоимость времени пребывания пассажиров в пути как расходную часть критерия

$$
C_{\text {пас-год }}^{\prime}=365 n_{\text {nac }} m \alpha_{\text {зап }}\left(T^{\prime}+T^{\prime \prime}\right) e_{\text {пас-час }} \cdot 10^{-6}, \text { млН. бел. руб./Год, }
$$

где $T^{\prime}+T^{\prime \prime}-$ время нахождения пассажиров в пути в направлении «туда» и «обратно», час.

В состав расходов входят капиталовложения в реконструкцию дороги $\left(K_{\text {рек }}\right)$ и на приобретение подвижного состава $\left(K_{\text {пс }}\right)$

$$
3_{t}=K_{\text {рек }}+K_{\text {пс }} \text {. }
$$

Кроме того, в связи с использованием нового подвижного состава в пассажирском движении и модернизацией технического состояния железной дороги после реконструкции изменятся эксплуатационные расходы как в пассажирском, так и грузовом движении. В частности, реализация более высоких скоростей требует больших затрат 
энергоресурсов, а улучшение плана трассы позволит уменьшить расходы на содержание пути в кривых. Уменьшение времени оборота подвижного состава влияет на потребность в локомотивных бригадах. Также следует учитывать дополнительные затраты, связанные с дополнительным простоем поездов из-за увеличения съема грузовых поездов скоростными пассажирскими. Поэтому в состав показателя критерия эффективности внедрения скоростного движения необходимо включить разницу эксплуатационных расходов, вызванных перестройкой и заменой подвижного состава $( \pm \Delta \mathrm{Ct})$.

Замена подвижного состава приводит к высвобождению используемых пассажирских вагонов и локомотивов. Поэтому необходимо учитывать его возвратную стоимость (К
Так как проект социальный и имеет большое значение для республики, то могут иметь место одноразовые дотации государства (Д).

Таким образом, с учетом изложенного, составляющие результата, полученного за счет эксплуатации объекта, определяются по формуле

$$
R_{t}=C_{\text {пас-час }}+Д+K_{\text {пс(возв.) }} \pm \Delta C_{t} .
$$

Общая экономическая эффективность использования подвижного состава ЭПМ «Stadler» (локализаџия производства в Беларуси - город Фаниполь)

Относительно

реконструкции железной дороги с целью внедрения скоростного движения пассажирских поездов чистый дисконтированный доход (ЧДД) определяется по формуле

$$
\text { ЧДД }=\sum_{t=0}^{T}\left(C_{\text {п-час }}+\text { Д }+K_{\text {пс(возв.) }} \pm \Delta C_{t}-K_{\text {рек }}-K_{\text {пс }}\right) \frac{1}{(1+E)^{t}} .
$$

В формуле (5) $\mathrm{C}_{\text {п-ч }}$, Д и $\mathrm{K}_{\text {пс (возв.) }}$ соответственно стоимость нахождения пассажира в пути, дотации государства и возвратная стоимость существующего подвижного состава при замене на новый улучшенный. Сумма этих трех составляющих и будет прибыльной частью ЧДД. Стоимость нахождения пассажира в пути определяется по формуле (2). Расчет стоимости времени пребывания пассажиров в пути с учетом использования подвижного состава "Stadler" на участке Красное - Минск - Брест (603, 1 км), по тяговым расчетам, составляет $\mathrm{T}^{\prime}=370,24$ мин (направление «туда») и в обратном направлении T "= 381,03 мин.

При этом, уменьшая время нахождения в пути за счет увеличения скорости, можно взимать дополнительную плату за сокращение времени поездки, увеличив стоимость пассажиро-часа. Например, существующую стоимость пассажиро-часа будем увеличивать, соответственно, в 1,5 и 2 раза (е = 6,6 бел.руб.).

Стоимость от продажи существующего подвижного состава, применяемого на участке, составит примерно 40 млн бел. руб. (по данным компании «Stadler»).

Дотации государства в данном случае будут незначительны, около 2 млн бел. руб.

Эксплуатационные расходы являются затратной частью ЧДД. К ним относятся расходы, зависящие от работы подвижного состава; расходы, не зависящие от работы подвижного состава; а также расходы на содержание постоянных устройств. С учетом единичных ставок и норм Республики Беларусь для участка Красное Минск - Брест эксплуатационные расходы $\Delta C_{\mathrm{t}}$ составят 62,25 млн бел. руб. на 1 поезд в сутки. Затраты на реконструкцию практически отсутствуют, так как закупается новый улучшенный подвижной 
состав с увеличенной скоростью прохождения кривых.

Стоимость закупки подвижного состава может быть различной. Что касается «Stadler», стоимость закупки 10 единиц составляет примерно 200 млн бел. руб.

Согласно приведенным выше расценкам, расчет ЧДД показан в табл. 1 .
Общий показатель ЧДД при различных стоимостях пассажиро-часа приводится на рис. 1.

Сроки окупаемости при различной стоимости пассажиро-часа в зависимости от размера движения представлены в табл. 2 и на рис. 2.

Таблица 1

Расчет ЧДД при использовании подвижного состава «Stadler»

\begin{tabular}{|c|c|c|c|c|c|c|c|c|}
\hline \multirow[t]{2}{*}{ Годы } & \multicolumn{3}{|c|}{$\begin{array}{c}\text { Затратная часть, } 3_{t} \text {, } \\
\text { млн бел. руб. }\end{array}$} & \multicolumn{3}{|c|}{$\begin{array}{c}\text { Доходная часть, } \mathrm{R}_{t}, \\
\text { млн бел. руб. }\end{array}$} & \multirow{2}{*}{$\begin{array}{c}\text { Коэффициент } \\
\text { приведения }\end{array}$} & \multirow{2}{*}{$\begin{array}{c}\text { чДД, } \\
\text { млн бел. } \\
\text { руб. }\end{array}$} \\
\hline & $\Delta C_{t}$ & $K_{\text {peK }}$ & $K_{\mathrm{px}}$ & $C_{\text {пас.год }}$ & Д & $K_{\mathrm{px}(\text { пов.) }}$ & & \\
\hline \multicolumn{9}{|c|}{$e_{\text {пас.час(суш) }}=6,6$ бел. руб. } \\
\hline 1 & 62,25 & 2 & 200 & \multirow{3}{*}{166,99} & 1 & 40 & 0,50 & $-47,63$ \\
\hline 2 & 68,48 & - & 0 & & - & - & 0,25 & 50,88 \\
\hline 3 & 75,32 & - & 0 & & - & - & 0,13 & 142,54 \\
\hline \multicolumn{9}{|c|}{$e_{\text {пас.час }}=9,9$ бел. руб. } \\
\hline 1 & 62,25 & 2 & 200 & \multirow{3}{*}{235,30} & 1 & 40 & 0,50 & $-13,48$ \\
\hline 2 & 68,48 & - & 0 & & - & - & 0,25 & 153,35 \\
\hline 3 & 75,32 & - & 0 & & - & - & 0,13 & 313,32 \\
\hline \multicolumn{9}{|c|}{$e_{\text {пас.час }}=13,2$ бел. руб. } \\
\hline 1 & 62,25 & 2 & 200 & \multirow{3}{*}{333,97} & 1 & 40 & 0,50 & 35,86 \\
\hline 2 & 68,48 & - & 0 & & - & - & 0,25 & 301,36 \\
\hline 3 & 75,32 & - & 0 & & - & - & 0,13 & 560,00 \\
\hline
\end{tabular}

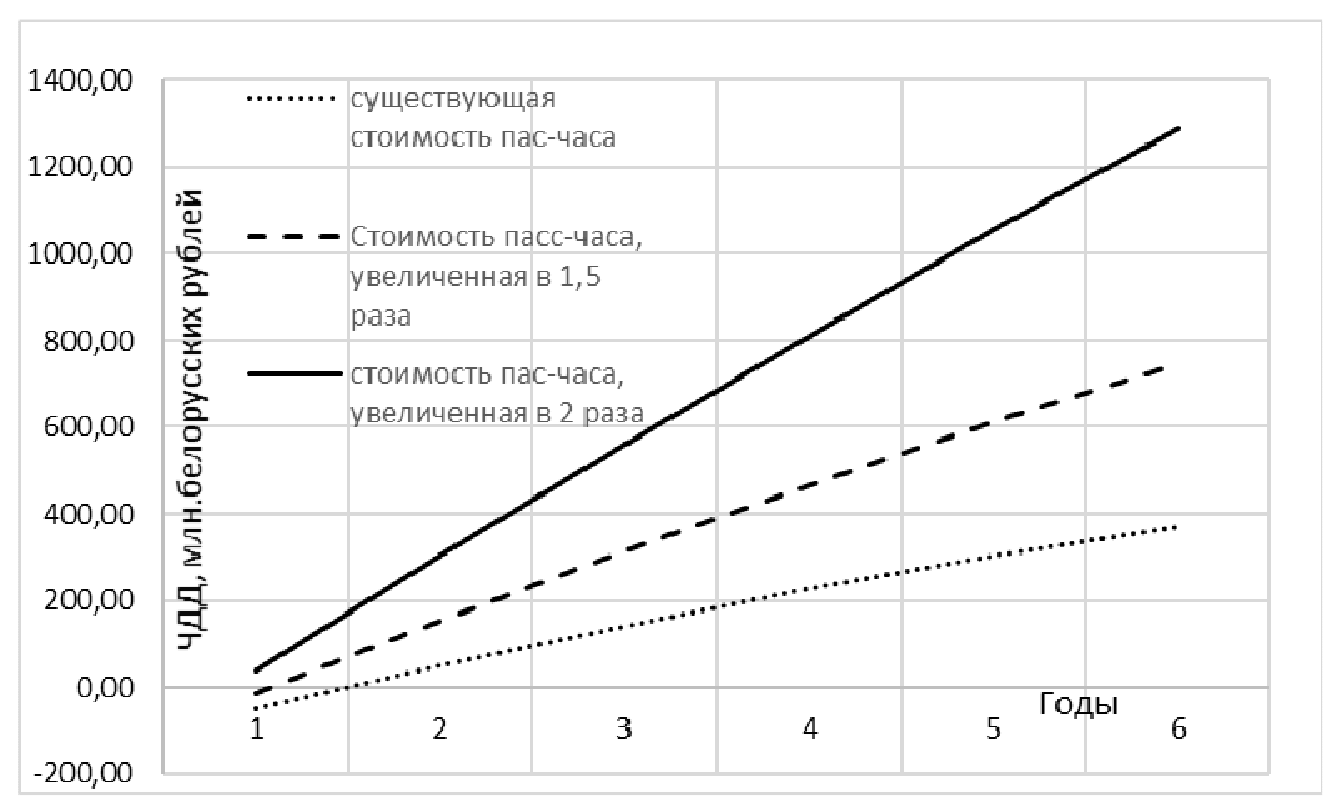

Рис. 1. Общий показатель ЧДД при различной стоимости пассажиро-часа:

1 - при стоимости пассажиро-часа, увеличенной в 2 раза; 2 - при стоимости пассажиро-часа, увеличенной в 1,5 раза; 3 - при существующей стоимости пассажиро-часа (6,6 бел. руб.) 
Сроки окупаемости при различной стоимости пассажиро-часа

\begin{tabular}{|c|c|}
\hline Срок окупаемости $\left(T_{\text {ок }}\right)$, год & Стоимость пассажиро-часа, бел.руб. \\
\hline 1,5 & 6,6 \\
\hline 1 & 9,9 \\
\hline 0,5 & 13,2 \\
\hline
\end{tabular}

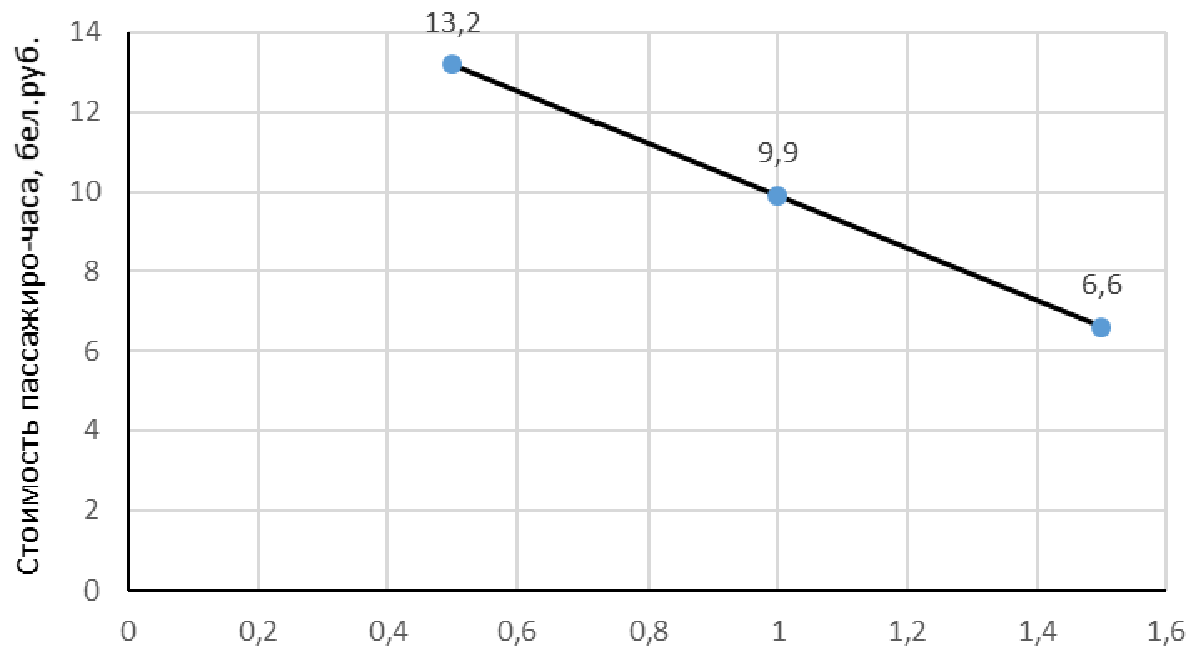

Рис. 2. Срок окупаемости введения скоростного движения при разной стоимости пассажиро-часа

Выводы. Из рисунков видно, что при существующей стоимости пассажиро-часа ЧДД станет положительным через 1,5 года и проект будет считаться выгодным. При увеличении стоимости пассажиро-часа в 1,5 раза проект окупится через полгода. При увеличении стоимости в 2 раза проект начнет окупаться практически сразу. Так как проект социальный, сокращение времени хода на 10 минут на участке в 603,1 км при существующей стоимости пассажиро-часа, а следовательно, и при существующей стоимости билетов, будет оптимальным вариантом.

\section{Список использованных источников}

1. Экономические изыскания и основы проектирования железных дорог: учеб. пособ. / Б. А. Волков, И. В. Турбин, Е. С. Свинцов, Н. С. Лобанова. Москва: Маршрут, 2005. 408 с.

2. Чередниченко А. Ю. Усовершенствование системы показателей работы железнодорожного транспорта в условиях его коммерциализации. Вестник Харьковского национального университета им. В. Н. Каразина. Харьков, 2002. Вып. 565. С. 104-106.

3. Курган Н. Б. Экономическая эффективность от устранения ограничений скорости движения поездов, обусловленная просрочкой ремонтов. Вестник Днепропетровского начионального университета железнодорожного транспорта имени академика В. Лазаряна. Днепропетровск, 2007. Вып. 19. С. 84-87.

4. Зозуляк В. П., Пасичник В. И. Показатели железнодорожного транспорта стран мира. Железнодорожный транспорт Украины. 2000. № 1. С. 16-21. 
5. Босов А. А. Повышение эффективности работы транспортной системы на основе структурного анализа: монография. Днепропетровск, 2005. 200 с.

6. Лапидус Б. М., Терешина Н. П., Трихункова Н. Ф. Экономика железнодорожного транспорта: учеб. пособ. Москва: УМК МПС России, 2001. 600 с.

7. Мямлин С. В. Оценка экономической эффективности инвестиционного проекта для железнодорожного транспорта с использованием различных методов. Вестник Днепропетровского национального университета железнодорожного транспорта имени академика В. Лазаряна. Днепропетровск, 2010. Вып. 33. С. 268-273.

8. Блохина А. С. Экономическая оценка мероприятий по внедрению новых профилей поверхности катания колес подвижного состава железных дорог. Вестник Днепропетровского наџионального университета железнодорожного транспорта имени академика В. Лазаряна. Днепропетровск, 2010. Вып. 31. С. 256-262.

9. Krink J., Vesterstrom, and Riget J. Particle Swarm Optimization with Spatial Particle Extension. To appear in: Proceedings of the Congress on Evolutionary Computation, 2002 (CEC 2002).

10. Givoni, M. Development and Impact of the Modern High-speed Train: A Review. Transport Reviews. Volume 26. Issue 5. 2006. P. 593-611.

Ковтун Павел Владимирович, канд. техн. наук, доцент, заведующий кафедрой проектирования, строительства и эксплуатации транспортных объектов Белорусского государственного университета транспорта.

Тел.: +375291887701. E-mail: sed@bsut.by.

Дубровская Татьяна Алексеевна, старший преподаватель кафедры проектирования, строительства и эксплуатации транспортных объектов Белорусского государственного университета транспорта.

Тел.: +375445545253. E-mail: rt-555@ yandex.ru.

Kovtun Pavel Vladimirovich, PhD (Tech.), Associate Professor, Department of Design, construction and operation of transport facilities, Belarusian State University of Transport. Tel.: +375291887701. E-mail: sed@bsut.by.

Dubrovskaya Tatyana Alekseevna, Senior Lecturer, Department of Design, construction and operation of transport facilities, Belarusian State Transport University. Tel.: +375445545253. E-mail: rt-555@ yandex.ru.

Статтю прийнято 15.10.2019 p. 